Paidéia, 2004, 14 (28), 177 -189

\title{
A DUALIDADE CUIDADO X EDUCAÇÃO NO COTIDIANO DO BERÇÁRIO ${ }^{1}$
}

\author{
Fabiana C. F. de Vitta ${ }^{2}$ \\ Universidade do Sagrado Coração \\ Maria Luisa G. Emmel \\ Universidade Federal de São Carlos
}

\begin{abstract}
Resumo: Esse trabalho objetivou verificar conceitos relativos ao cuidar e educar, junto a profissionais de berçário. Foram estudados documentos sobre educação infantil e realizadas entrevistas e observações da prática de sete profissionais de berçários, com enfoque nas atividades de cuidados desenvolvidas com as crianças. Os dados foram organizados segundo categorias: função do berçário, conceito de educar e de cuidar e sofreram análise qualitativa, permitindo a confrontação entre o material empírico e o teórico. Os resultados mostraram que os documentos oficiais pouco discutem a fase em questão, deixando imprecisa a relação entre as atividades de cuidado e seu papel educacional. Essa imprecisão se reflete no discurso das profissionais do berçário. As atividades de cuidados passam a estar contidas na educação da criança, na medida em que, na visão das profissionais, têm função disciplinadora. Esse aspecto justifica-se pela falta de formação e pelo fato de vincularem esta atividade às suas experiências de mães.
\end{abstract}

Palavras-chave: cuidar; educar; berçário.

\section{THE DUALITY BETWEEN CARE AND EDUCATION IN A NURSERY DAILY ACTIVITIES}

\begin{abstract}
This article has the as objective to verify concepts related to care and to educate, with nursery professionals. Some documents about children education were studied and some interviews and observations of the work were done with seven nursery professionals. The main focus were the activities related to care developed with children. Data were organized following the degrees: function of the nursery, education and care concepts. Data were submitted of quality analysis, allowing the confrontation between the theorical and empirical material. The results showed that official documents do not worry about the phase under discussion, letting inaccurate the relation between the activities of care and its educational role. This inexactness is noticed in the nursery professionals' speech. The activities of care are enclosed in child education, once in the vision of the professionals it has a corrective function. This aspect is justified by the lack of formation and by the fact of they entail this activity to their mothers' experience.
\end{abstract}

Key-words: care; education; nursery.

O homem, desde o nascimento, tem seu desenvolvimento percepto-cognitivo, motor e sócioemocional promovido por sua interação com o meio no qual está inserido. Suas experiências, atividades e ações sobre o ambiente promovem essa interação e, conseqüentemente, permitem o desenvolvimento de suas potencialidades e habilidades (Cavicchia,

\footnotetext{
${ }^{1}$ Artigo recebido para publicação em 29/09/2003; aceito em 27/11/2003 ${ }^{2}$ Endereço para correspondência: Fabiana C. F. de Vitta, Rua Américo Persin, 158, Parque Pontal, Piratininga, SP, Cep 17490-000, E-mail: devitta@iplus.com.br
}

1993; De Vitta, 1998; Eckert, 1993; Thiessen \& Beal, 1995).

Existem atividades que são próprias de cada idade e que permitem aprendizagens apropriadas às suas características e necessidades particulares, sendo indiscutível sua importância para o desenvolvimento das diferentes faculdades do sistema nervoso central na criança de 0 a 18 meses, sendo que a falta de estimulação adequada ao bebê, prejudica a aquisição dos movimentos e do desenvolvimento da com- 
preensão de mundo (Béziers \& Hunsinger, 1994; Eckert, 1993; Thiessen \& Beal, 1995).

Nessa faixa etária, a maioria dos cuidados dispensados à criança advém de dois núcleos, que cada vez estão mais próximos e interdependentes: a família e a escola, focos de vários trabalhos (Eltink, 2000; Rapoport \& Piccinini, 2001; Rossetti-Ferreira, Amorim \& Silva, 2000) que objetivaram verificar sua interferência no desenvolvimento da criança e, também, a interação existente entre as mesmas. Os espaços mais utilizados para tais estudos são o lar, a creche e a pré-escola, que representam as instituições educacionais que no Brasil atendem às crianças de 0 a 6 anos.

No Brasil, a creche foi introduzida para cuidar das crianças das mulheres que trabalhavam fora e foi regulamentada em 1972 pelo governo brasileiro, que decretou a obrigatoriedade do funcionamento de creches ligadas a empresas privadas e/ou públicas. Sofreu influência direta do pensamento médico e, mais tarde, do assistencialista, sendo que as condições de funcionamento implicavam na garantia da saúde das crianças. No fim da década de 80 e década de 90 , o atendimento à criança de 0 a 6 anos passou a ser garantido por lei, distinguindo-se a educação infantil, agora parte do sistema de ensino, dos cuidados de saúde e assistenciais, oferecidos pelo SUS (Amorim, Yazlle \& Rossetti-Ferreira, 1999). A educação infantil incorporou duas instituições distintas, definidas pela Lei de Diretrizes e Bases da Educação Nacional (LDB), promulgada em dezembro de 1996: a creche ou entidades equivalentes para crianças de 0 a 3 anos e a pré escola, para as de 4 a 6 anos.

No entanto, o papel da creche ainda está pouco definido. Leis atuais mostram grande preocupação com essa problemática. A Constituição Brasileira de 1988 garante o direito à educação e cuidados para as crianças de 0 a 6 anos, afirmando a indissolúvel tarefa de educar e cuidar das crianças nessa faixa etária. Essa afirmação é regulamentada, também, na LDB (Fullgraf, 2001; Mazzilli, Rosalen, Barbosa, Giacomini \& Rozineli, 2001). Kuhlmann Jr. (1999) ressalta que educar a criança é uma ação integrada ao cuidá-la, ou seja, uma não exclui a outra.

As atividades que envolvem o cuidar do bebê em creche, exigem uma rotina organizada, caracteri- zada por alimentação, higiene, descanso e recreação. Batista (2001), escrevendo sobre o proposto e o vivido em relação ao dia-a-dia da creche destaca que há certa rigidez nas atividades propostas às crianças, sendo que essas têm por objetivo prever os acontecimentos e dirigir e organizar o tempo e o espaço. No entanto, essa atitude vai de encontro à prática natural da criança, constituída pela simultaneidade de ações.

Nas creches, os profissionais do berçário deverão assumir um duplo papel: o de alguém que "cuida" ou "toma conta" das crianças e o de educador, que contribui ativamente para seu desenvolvimento global. O conhecimento que os profissionais do berçário têm sobre o desenvolvimento infantil é um dos fatores que determinam a qualidade do atendimento feito à criança. Strenzel (2001) diz que a formação desses profissionais, ou sua ausência, implica no comprometimento da prática pedagógica desenvolvida.

Muitas pesquisas têm discutido qual seria a melhor forma de possibilitar a esses profissionais maior entendimento de sua prática, assim como formas de aprimorá-la (Azevedo e Schnetzler, 2001; Mello, 2001; Silva \& Rossetti-Ferreira, 2000; Strenzel, 2001). Os resultados dessas pesquisas indicam que é necessário que se respeite a prática já existente e, a partir dela, se construa o conhecimento necessário à melhora da qualidade da educação da criança em creche. Segundo Strenzel (2001), há urgência na reflexão sobre essa dualidade de papéis: cuidadora e educadora. A autora aponta para a necessidade da formação continuada dos profissionais da creche, que permita a reflexão sobre suas práticas, relacionando-as com os contextos de vida das crianças.

Silva e Rossetti-Ferreira (2000) destacam que cuidado e educação são indissociáveis quando se considera as especificidades do desenvolvimento da criança de 0 a 6 anos. Essas autoras sugerem que as discussões e estudos se direcionem para o distanciamento entre discurso e prática e a necessária reflexão para que os avanços não se restrinjam ao papel e sejam realmente efetivados. Ressaltam que cabe aos pesquisadores e formadores "identificar e compreender as motivações e as redes de sustentação das reservas e oposições aos avanços legais e sugeridos pelo conhecimento na área” (p.6).

As leis e as pesquisas na área não afetaram 
necessariamente a prática, pois a formação dos profissionais que atuam na educação infantil (com crianças de 0 a 3 anos) traz consigo muitos problemas a serem resolvidos. Segundo Azevedo e Schnetzler (2001), o que tem sido apontado como apropriado em relação à educação das crianças levará tempo para ser colocado em prática, diferenciando-se do que tem sido desenvolvido nas escolas de educação infantil.

Amorim, Yazlle e Rossetti-Ferreira (1999) destacam que os documentos oficiais têm sido publicados com o objetivo de garantir qualidade na educação infantil. No entanto, contemplam poucos aspectos relacionados à saúde física e à formação do professor para promover o desenvolvimento integral da criança com competência e qualidade. Palhares e Martinez (1999) ao comentarem sobre o Referencial Curricular Nacional para a Educação Infantil RCNEI - publicado em 1998 pelo MEC, ressaltam a distância entre o que é proposto e o que acontece na realidade, principalmente no que concerne ao papel das educadoras. Entretanto, é necessário destacar que a qualidade do serviço oferecido pela creche não diz respeito apenas à formação do profissional que lida diretamente com a criança. Depende de toda uma organização social, representada pelas leis e pela organização pedagógica das instituições.

Quando se pensa em estudar a creche, mais especificamente o berçário e as atividades nele desenvolvidas, há necessidade de saber como se processa e se organiza a rotina diária, levando em consideração os seus diferentes elementos constituintes: os profissionais e a prática propriamente dita. A partir da análise desses elementos, será possível vislumbrar a realidade e os aspectos que a constituem e, assim, propor mudanças significativas através da interferência nos pontos necessários.

A investigação aqui proposta lançou o seu olhar sobre as atividades relativas ao cuidado das crianças de 0 a 18 meses que freqüentam a creche e seu papel na educação das mesmas, tendo como princípio que essa educação refere-se à oportunidade de desenvolver-se globalmente, como definido pelos objetivos gerais da educação infantil, segundo o RCNEI (Brasil, 1998, p. 63).

Dessa forma, esse trabalho teve por objetivo verificar os conceitos relativos ao cuidar e educar, junto aos profissionais de berçário, em instituições de educação infantil. Insere-se no campo da Pesquisa Social, pois como relata Minayo (2000, p.23), “o termo Pesquisa Social tem uma carga histórica e, assim como as teorias sociais, reflete posições frente a realidade, momentos do desenvolvimento e da dinâmica social, preocupações e interesses de classes e de grupos determinados”.

\section{Método}

A primeira etapa dos procedimentos metodológicos para a implementação dessa pesquisa consistiu em uma fase exploratória, que teve por objetivo contextualizar o objeto da pesquisa, entendido como as atividades relativas ao cuidado da criança de 0 a 18 meses que freqüentam a creche e seu papel na educação das mesmas. Para essa etapa, o procedimento utilizado foi a pesquisa bibliográfica.

A segunda etapa objetivou o encontro com os fatos empíricos, ou como definido por Minayo (2000), tomar como material as representações sobre o papel da atividade no desenvolvimento infantil no berçário tais como são manifestadas pelos atores sociais, as profissionais. Implica em considerar as comunicações individuais (entrevistas) e as observações de condutas e costumes relativos às atividades (observação).

Para isso, foram entrevistadas sete funcionárias que atuam no berçário das duas escolas de educação infantil - creches - integradas à Secretaria Municipal de Educação de Bauru. A escolha dessas instituições deve-se à proximidade que têm em relação às novas exigências da LDB, ou seja, já fazem parte da Secretaria de Educação.

É necessário ressaltar que o número de participantes da pesquisa é restrito devido à metodologia escolhida e objetivo da pesquisa. Thiollent (2002) coloca que, na prática da pesquisa convencional, a representatividade dos grupos por critérios qualitativos costuma recorrer a "amostras intencionais", ou seja, pequeno número de sujeitos escolhidos intencionalmente devido à relevância que apresentam em determinado assunto. Acrescenta que "(...) o princípio de intencionalidade é adequado no contexto da pesquisa social com ênfase nos aspectos qualitativos, onde todas as unidades não são consideradas como equivalentes, ou de relevância igual” (p. 62). 
Após a aprovação da pesquisa pelo Comitê de Ética em Pesquisa e autorização formal de todos os participantes, tiveram início as observações do berçário, para as quais foi utilizado um caderno de anotações. Essas eram realizadas ao final de cada observação e, inicialmente, referiram-se à rotina no berçário e às considerações feitas pelas funcionárias. As observações tiveram importante papel na definição dos temas a serem tratados nas entrevistas com as profissionais.

Para esta pesquisa, a entrevista semiestruturada pareceu ser a mais adequada, por ser guiada por uma relação de pontos de interesse sem a imposição de uma ordem rígida, que o entrevistador vai explorando ao longo de seu curso.

Nesta pesquisa a entrevista foi norteada por tópicos escritos numa folha, de modo que todos os entrevistados pudessem discorrer livremente sobre os mesmos temas. $\mathrm{O}$ roteiro foi preparado baseado no objetivo da pesquisa, em referencial bibliográfico da área e na observação realizada na etapa anterior.

As entrevistas foram individuais e ocorreram na própria creche, em horário previamente combinado por entrevistador e entrevistado. Foram gravadas em fitas cassetes, na íntegra. Durante e após a entrevista, foram realizadas anotações sobre linguagem gestual, expressões faciais, ou seja, sobre a linguagem não-verbal que ocorre concomitantemente à verbal, considerada importante para a compreensão e a validação do que foi efetivamente dito (Gil, 1999; Lüdke \& André, 1986; Minayo, 2000).

Os passos para a análise do material incluíram a ordenação dos dados obtidos através da transcrição das fitas cassete das entrevistas, leitura e organização dos relatos e organização dos dados de observação. Em seguida, os dados foram classificados após releitura dos textos, permitindo apreender as estruturas de relevância dos participantes e as idéias centrais transmitidas sobre o tema em foco. Também foi realizada a leitura transversal de cada material, fase em que se organizou o material em temas: função do berçário, conceito de educar e conceito de cuidar.

A análise final permitiu a confrontação entre os resultados do material empírico e o teórico, bus- cando as relações dialéticas entre ambas, conforme propõe Minayo (2000).

\section{Resultados e Discussão}

Os dados obtidos permitiram entender a organização dos berçários nas creches e a organização das mesmas na estrutura da Secretaria Municipal de Educação de Bauru. E possibilitaram identificar os conceitos relativos ao cuidado e educação da criança de 0 a 18 meses atendidas nessas instituições.

\section{A Situação dos Berçários na Cidade de Bauru}

São 11 as creches da cidade de Bauru sob a direção da Secretaria do Bem Estar Social (SEBES) que, de acordo com as propostas do Ministério da Educação - Lei de Diretrizes e Bases 9394/96, passaram a fazer parte da Educação Infantil. Sendo que, em Bauru, essas modificações estão sendo realizadas de forma gradativa. Em 2001 foi elaborado o Projeto Integração: Educação infantil - creche e pré-escola, pela equipe do Departamento de Educação Infantil da Secretaria Municipal de Educação (SME), contendo, dentre outros tópicos, um cronograma previsto para a incorporação das creches à Secretaria.

A primeira etapa desse projeto prevê o atendimento a um número crescente de creches, através da colocação de diretores e professores com o objetivo de ressignificar a prática construída pela equipe de trabalho da SEBES, que continuaria a auxiliar na infra-estrutura física, material e de funcionários.

Essa pesquisa foi desenvolvida junto às duas creches que possuíam berçário, ambas já sob administração da SME. A partir dos dados fornecidos pela SME, através da responsável pela área de educação infantil, pela diretora dessas duas creches, pelas profissionais que trabalham no berçário e através da observação direta realizada pela pesquisadora, foi possível organizar um quadro descritivo das creches e das atividades realizadas junto às crianças do berçário.

Observou-se que as atividades que constituem a rotina de ambos os berçários são as mesmas, havendo pequenas variações quanto aos horários e a disponibilidade do espaço físico, recursos materiais 
e humanos. Esta última variável - recursos humanos - é a maior responsável pelas variações organizacionais existentes nas duas creches, devido ao tempo de serviço no berçário e a definição das funções relativas ao cargo que exercem os funcionários.

A instituição cujas profissionais trabalhavam juntas há cerca de cinco anos, apresentava uma rotina mais organizada e adaptada às necessidades de cuidados da criança. Havia maior tolerância em relação aos horários e às intercorrências diárias não planejadas (tanto com as crianças como com as próprias profissionais). No entanto, apresentavam maior resistência à possibilidade de introdução de mudanças na rotina do berçário, em estudo na SME.

A falta de definição de funções para as profissionais, ou ainda, aglomeração de diferentes funções para um só cargo - Auxiliar de Creche -, foi um dos problemas mais graves observados na realidade dos berçários.

Em Bauru, as profissionais que lidam com o berçário são contratadas como auxiliares de creche, ou seja, desempenham diferentes funções, geralmente, ao mesmo tempo. Essas funções incluem o cuidado com as crianças, a limpeza e organização do ambiente físico, organização da alimentação no berçário e, invariavelmente, substituição de funcionários faltosos no espaço da creche. É necessário destacar que a limpeza do ambiente do berçário é diária e deve ocorrer no tempo livre dessas profissionais e, a da creche como um todo, ocorre durante as reuniões pedagógicas dos professores, às quais as auxiliares não participam por pertencerem a SEBES, e durante recessos e feriados escolares ligados à SME.

Essas auxiliares, segundo a responsável pela educação infantil do município, não podem participar do trabalho contínuo de formação implementado pela SME, por pertencerem à outra secretaria, recebendo apenas apoio e orientação da diretora e de professores. Está em estudo a viabilização de projetos que possam envolver esses profissionais e promover sua formação continuada, através do departamento pedagógico da SME.

Em Campinas, a situação é diferente (Ávila, 2002), pois no contexto do trabalho com a criança de 0 a 3 anos, há professores e monitores contratados, sendo que os primeiros tratam das questões reconhe- cidas como pedagógicas e os últimos das ligadas aos cuidados físicos, alimentares e higiênicos, reconhecendo um caráter tanto escolar quanto familiar/doméstico na educação infantil.

No entanto, tanto em Campinas como em Bauru, as diferenças relacionadas a essa distinção entre professores e cuidadores, incluem também diferenças de escolaridade, salariais, na duração da jornada de trabalho, no prestígio e auto-estima. Em Bauru, isso torna-se mais grave por estarem as auxiliares ligadas à outra Secretaria que não a de Educação (Secretaria do Bem Estar Social), ou seja, pertencem a grupos distintos.

Essa discussão propicia o aprofundamento de um tema relevante: qual a função do berçário?

\section{Função do berçário}

Na maior parte dos discursos das profissionais do berçário, é possível observar que impera a idéia de que a creche existe para atender às crianças cujas mães têm que trabalhar. Esse discurso vem, em alguns casos, imbuído de ressentimento em relação à família pela carência que a criança sofre, sob seu ponto de vista. Essa idéia é esclarecedora quanto aos motivos pelos quais o berçário tem por objetivo principal (segundo as entrevistadas) suprir, junto à criança, as necessidades básicas que deveriam ser atendidas pela família.

A observação da rotina do berçário possibilitou verificar que as profissionais (não só do berçário, mas da creche e da administração) classificam as crianças como pertencentes às famílias com problemas (financeiro, matrimonial, etc.) que impossibilitam cuidar e educar (educar entendido como disciplinar) a criança de modo satisfatório. Assim, o berçário tem a importante função de "substituir" a família.

Esse conceito faz parte do senso comum e espelha-se na extrema carência da população atendida pela maioria das instituições de educação infantil públicas, ou seja, além da mãe estar ausente durante grande parte do dia da criança, há um conjunto de fatores que prejudicam ainda mais a "criação" dessa criança por parte da família, como: falta de recursos materiais (fraldas, alimentação), falta de recursos 
básicos (água, luz, serviços de saúde), falta de recursos pessoais (baixíssima escolarização, famílias desfeitas) etc.

Em vários discursos, foi possível observar contradição na definição da função da creche, ou seja, sempre se buscou vínculos com seu papel assistencialista e, embora as pessoas tentem incorporar objetivos educacionais, contradizem-se ao falar que se a família da criança tem condições de ficar com ela, não deveria colocá-la no berçário. Isso é claro no modelo de seleção das crianças para entrarem no berçário: devido ao número reduzido de vagas, são chamadas aquelas cujas condições sócio-econômicas são piores e cujas mães estejam trabalhando fora, devendo haver inclusive, adequação de crianças no berçário por mandato do Juizado de Menores.

A creche ainda escolhe suas crianças de acordo com a necessidade social da família, não reconhecendo um direito adquirido por lei (LDB) de que todas as famílias que desejarem que o Estado cuide e participe da educação de seus filhos, devem ter vagas garantidas em creches e pré-escolas públicas. No entanto, essa proposta além de ainda não ser incorporada pelos que administram essas instituições, depara-se com a real falta de vagas para a inclusão de todas as crianças que as solicitam. Segundo Cerisara (2002) permanece o conceito de que as vagas das creches públicas devem favorecer as crianças cujas mães trabalham fora e ganham pouco. Esse fato remete à lembrança da implantação das creches no Brasil, como direito das mulheres trabalhadoras que têm filhos.

Essa confusão de papéis da creche pode ser vista também por parte da família, que acredita ser obrigação do berçário cuidar de suas crianças. A relação dos membros da família com as profissionais nem sempre favorece o respeito entre elas e a distinção de papéis: mãe $\mathrm{x}$ funcionária (que deveria ser professora).

Outro ponto verificado nas entrevistas e nas observações é que a função do berçário está diretamente relacionada à função das profissionais, ou seja, sendo elas auxiliares de creche, teoricamente capacitadas para cuidar das crianças no sentido de prover os cuidados essenciais, o berçário tem função de prover esses cuidados. A queixa relacionada à falta de materiais relaciona-se a essa função, ou seja, materiais de limpeza, para alimentação, vestuário e higiene. Quando se refere aos brinquedos, apenas incorpora a monotonia e a incompletude dos doados sem qualquer preocupação com o contexto da rotina diária. Outra queixa freqüente no dia-a-dia das auxiliares está diretamente vinculada com a função a elas atribuída, ou seja, gostariam de participar de cursos que esclarecessem o que elas devem fazer com a criança. No entanto, é necessário ressaltar que a dúvida quanto à função esteve mais presente em uma das instituições, parecendo estar relacionada aos problemas de organização interna da creche, contexto sócio-cultural do bairro onde se insere, período de organização interna do berçário, posto que as profissionais estavam trabalhando juntas há pouco tempo. No berçário onde as profissionais tinham maior tempo de trabalho conjunto, as funções de cuidados estavam incorporadas, sendo apresentadas tanto na rotina do dia-a-dia, como no discurso.

\section{Então, o que é cuidado no contexto do berçário?}

Após definidas pela Lei as funções da educação infantil, foi organizado pelo Ministério da Educação o Referencial Curricular Nacional, concernente às diferentes etapas da educação e que se coloca como proposta educacional aberta, flexível e não obrigatória.

Nos volumes do Referencial Curricular Nacional para a Educação Infantil (RCNEI), são discutidos os conceitos relativos ao cuidar, que é entendido como:

"ajudar o outro a se desenvolver como ser humano. Cuidar significa valorizar e ajudar a desenvolver capacidades. O cuidado é um ato em relação ao outro e a si próprio que possui uma dimensão expressiva e implica em procedimentos específicos. O desenvolvimento integral depende tanto dos cuidados relacionais, que envolvem a dimensão afetiva e dos cuidados com os aspectos biológicos do corpo, como a qualidade da alimentação e dos cuidados com a saúde, quanto da forma como esses cuidados são oferecidos e das oportunidades de acesso a conhecimentos 
variados." (Brasil, 1998, p.24).

Nota-se nessa proposta, que o cuidado envolve aspectos afetivos, emocionais e cognitivos, estando intimamente relacionado com a proposta de educação.

No entanto, o que se observa nas rotinas da maior parte dos berçários, são práticas baseadas no papel de cuidar, pela própria especificidade da faixa etária. Esse dado, entrementes, não deveria ser visto como um entrave, e sim como característica da educação infantil para essa faixa etária. Histórica e culturalmente, a criança pequena é vista como um ser que deve ser cercado de cuidados de modo a proporcionar um desenvolvimento sadio, principalmente $o$ relativo ao seu estado físico: saúde $\mathrm{x}$ doença (Amorim, Yazlle \& Rossetti-Ferreira, 1999; Coutinho, 2002; Felipe, 2001; Prates \& Oliveira, 2001). Dessa forma, o cuidar engloba as atividades de higiene, alimentação e sono.

No discurso de todas as profissionais participantes, os cuidados apareceram como função principal das atividades oferecidas, sendo que muitas ressaltaram a proximidade com a educação. No entanto, em muitos discursos, as atividades de cuidados são realizadas dentro de uma rotina que envolve espaço e tempo limitados e os atos são automáticos, obedecendo a uma ordem que auxilie na organização dessa rotina. Para muitas, nesse automatismo perdese a oportunidade de interação com a criança e, conseqüentemente essa proximidade entre cuidado e educação não se efetiva na prática.

Durante as entrevistas, confirmou-se o que já havia sido visto nas observações quanto à participação da criança dentro desse ritual diário, ou seja, ela é passiva de cuidados, sendo que, para as profissionais, a educação embutida nessas atividades é propiciada por falarem para a criança o que está sendo realizado.

Sendo a criança passiva de cuidados, esses, em alguns casos, compreendem também situações nas quais a profissional deva evitar o perigo, cuidado como sinônimo de proteção da criança.

Ávila (2002), ao estudar a realidade de uma instituição de Campinas, ressalta que a creche sempre foi educativa, mesmo quando se ligava à Promoção Social, o que, para a autora, é diferente de ter intencionalidade educativa. Isso poderia ser alterado com a mudança ou inserção, no quadro de funcionários, de profissionais formados para lidar com práticas educativas. No entanto, essa alteração esbarra na realidade brasileira, a formação da maioria das professoras não contempla a educação das crianças de 0 a 3 anos.

E o que é a educação no contexto do berçário? Segundo o mesmo Referencial (Brasil, 1998), educar significa:

"propiciar situações de cuidados, brincadeiras e aprendizagens orientadas de forma integrada e que possam contribuir para o desenvolvimento das capacidades infantis de relação interpessoal, de ser e estar com os outros em uma atitude básica de aceitação, respeito e confiança, e o acesso pelas crianças, aos conhecimentos mais amplos da realidade social e cultural. Neste processo, a educação poderá auxiliar o desenvolvimento das capacidades de apropriação e conhecimento das potencialidades corporais, afetivas, emocionais, estéticas e éticas na perspectiva de contribuir para a formação de crianças felizes e saudáveis.” (p.23).

Vincular o conceito de educar com o desenvolvimento da criança, ou melhor, ao favorecimento do desenvolvimento da criança em seus planos motor, cognitivo, perceptual, emocional e social como sugere o RCNEI, implica em haver planejamento das profissionais em relação às atividades que irão propor para as crianças. Esse texto diz que se deve propiciar situações de cuidados, brincadeiras e aprendizagens orientadas de forma integrada, ou seja, é necessário planejar cada atividade para que seus elementos constituintes contribuam com o desenvolvimento da criança.

No entanto, todas as entrevistadas disseram não saber exatamente as habilidades a serem adquiridas pela criança nas diferentes idades. Baseiam-se na experiência de mães e na prática que têm no berçário.

Observou-se que o conceito de educar vincula-se à formação moral da criança, ou seja, a ensinar o certo e o errado, a conviver bem com as outras cri- 
184 Fabiana C. F. de Vitta

anças e adultos, a ter bons modos e a aprender a cuidar de si. Quanto à prática, observou-se que o comportamento das profissionais nas atividades de rotina do berçário promove a educação no sentido de disciplinarização das crianças em relação aos hábitos de higiene, alimentação e convívio social, ou seja, a maioria das verbalizações indica à criança o que é certo fazer naquela situação.

Em relação à aprendizagem de conceitos, o mais claro, presente na maioria dos discursos, diz respeito à nomeação das partes do corpo. Em alguns discursos observa-se uma ampliação dessa idéia para a aprendizagem de cores, função de objetos e outros conceitos formais.

Quanto ao desenvolvimento de habilidades de linguagem, motoras e cognitivas, as profissionais disseram não saber o que deve ser ensinado ou promovido para cada idade das crianças do berçário, o que se torna ainda mais difícil pela falta de planejamento pedagógico e de estabelecimento de objetivos para essa faixa etária.

O brincar está, no discurso das profissionais, relacionado à educação, sendo considerado pela maioria, importante para o desenvolvimento da criança, proporcionando situações para a aprendizagem. Pereira e Emmel (1999) reiteram estes pressupostos, destacando que nos primeiros anos de vida o adulto serve como modelo e provedor da brincadeira da criança, sendo uma figura fundamental para o seu desenvolvimento emocional. No entanto, o brincar não faz parte das atividades de rotina, os profissionais não têm planejamento e não sabem o que pode ser desenvolvido durante esses momentos, ou seja, são atividades desestruturadas, sem objetivos e realizadas ao acaso, nos momentos de folga da rotina. Parece ser algo inerente à criança, e não uma das funções das profissionais ou da instituição.

O brincar é pensado em termos de objetos e a função destes, sendo que não pensam em como adaptá-los para objetivos ligados ao desenvolvimento da criança. Não foi observado o brincar sem objetos, exceção feita à algumas vezes que uma das profissionais brincava de pegar com uma das crianças.

No brincar, assim como nas atividades de cuidado, o que dirige a ação das profissionais é a experiência pessoal, ou seja, a vivência que têm da atividade, aprendida quando criança (no caso do brin- car) ou com o desenvolvimento do papel de mãe.

As entrevistas realizadas nessa pesquisa mostraram claramente a força do ser mãe na definição de suas práticas, sendo que na maioria das vezes, o conceito de atividade educativa inerente às atividades de cuidado passava pelo olhar de mãe, ou seja, de educação para a disciplina e "bons modos".

Ávila (2002) encontrou resultados semelhantes em um estudo de caso que tinha por objetivo descrever, analisar e discutir as práticas educativas no contexto das relações profissionais junto às monitoras de educação infantil e às crianças, num Centro Municipal de Educação Infantil de Campinas. Essa autora aprofundou-se na literatura sobre esse tema e constatou que é de grande relevância assumir que o educador infantil é um profissional do gênero feminino e os diferentes papéis assumidos por elas afetam a atuação docente.

É necessário destacar, no entanto, que outras justificativas se juntaram na explicação do conhecimento em relação às atividades oferecidas às crianças. Essas dizem respeito ao tempo de prática com essa população, à aprendizagem com outras funcionárias que trabalhavam no berçário, à observação da prática das funcionárias que estavam no berçário há mais tempo e a cursos oferecidos pelas diferentes secretarias (SME e SEBES).

Enfim, no berçário trabalha-se com cuidado ou educação?

\section{Cuidado ou educação?}

A Lei 9394/96, artigos 29 a 31, expressa a forma de pensar a creche enquanto instituição de educação, tendo como um dos pontos principais a finalidade da educação infantil: o "desenvolvimento integral da criança até seis anos de idade, em seus aspectos físico, psicológico, intelectual e social, complementando a ação da família e da comunidade" (Souza \& Silva, 2001, p.51).

Quando se pensa em desenvolvimento nas áreas acima descritas, está se aludindo a uma criança que se insere em um contexto e que nele desenvolve habilidades e competências. Isto ocorre pela interação direta entre o ser biológico e o ambiente.

O ser humano desenvolve-se a partir da es- 
treita relação do organismo com o meio que o envolve, que o insere num contexto cultural e social. Através de seu aparelho sensorial a criança capta informações do ambiente, as integra em seu sistema cognitivo e age, provocando mudanças que propiciarão nova interação com o ambiente. Esse ciclo de ações da criança sobre o meio e vice-versa, tanto recebe influência como influencia a organização emocional e social da criança. Ou seja, é através da interação da criança com o meio, que sua auto-estima se desenvolve e organiza um quadro acerca do mundo onde está inserida, propiciando maior ou menor satisfação consigo mesma e com a vida que tem.

As atividades da rotina da criança são as grandes responsáveis por promover a relação entre ela e o ambiente que a cerca. Através dessas atividades, a criança irá organizar suas sensações e suas ações sobre os objetos e pessoas, dando significado às situações cotidianas, o que possibilitará construir uma idéia de mundo.

Kuhlmann Jr. (1999) destaca que se o desenvolvimento da criança acontece pela interação com a realidade social, cultural e natural, é preciso organizar uma proposta educacional que lhe permita conhecer esse mundo, de acordo com suas particularidades, ou seja, deve-se possibilitar à criança experiências diversas que a auxiliem na construção de seu conhecimento.

Mas como pensar nessa proposta educacional na rotina do berçário, cujas atividades direcionamse aos cuidados com a criança?

Segundo Kuhlmann Jr. (1999) a instituição de educação infantil adquire sentido como um lugar de cuidado e educação numa perspectiva integrada, quando toma a criança como ponto de partida para a formulação de propostas pedagógicas. Bujes (2001) chama a atenção para um caráter próprio da educação infantil, no qual cuidar não deve seguir o modelo da família e educar, não pode ter o mesmo modelo que a escola, pois na educação infantil, o conhecimento escolar envolve, além do desenvolvimento de formas de pensar, também, formas de sentir, de fazer (com o corpo), de expressão e de manifestação de gostos. Para a autora, a experiência de educação infantil tem que ser muito mais qualificada.

Coutinho (2002) ao discutir as atividades de cuidado e as de educação propõe que se encontre nas primeiras, espaços para a valorização de momentos de interação que podem ser considerados no âmbito da educação, mas ressalta que as atividades de cuidados estão tão arraigadas ao conceito assistencial que condicionam as ações das profissionais.

Essa dualidade pôde ser observada no cotidiano das instituições pesquisadas e nas entrevistas com as profissionais. A rotina de cuidados rege o cotidiano do berçário, ou seja, os horários e as atividades são organizados de acordo com o número de crianças em função das atividades de higiene, alimentação e sono. Outras atividades, traduzidas como brincar, que no discurso das profissionais é a única atividade citada primeiramente como educativa, são encaixadas nas horas vagas dessa rotina.

Todas as atividades que podem ser entendidas facilmente como cuidados (higiene, sono e alimentação), explícita ou implicitamente denotavam uma organização prévia que incluía materiais, espaço físico e clientela, ainda que fossem realizadas mecanicamente. Para as atividades relacionadas ao brincar, a proposição era automática, "natural”, "sem planejamento", segundo as próprias profissionais.

Esses dados foram encontrados na pesquisa realizada por Coutinho (2002). A autora mostra, que apesar de para as berçaristas os momentos de cuidado e de educação serem importantes, são desconsiderados do planejamento do cotidiano educativo.

Campos (2002) ressalta que a divisão da educação infantil segundo a faixa etária é um dado relevante para se pensar na formação de profissionais para a educação infantil. Para a autora, as diferenças na formação de profissionais para essas instituições “deve se basear nas características da faixa etária e não na vinculação burocrática da instituição educativa ou em uma determinada visão de educação” (p. xiv). Kuhlmann Jr. (1999) concorda com essa observação.

Cerisara (2002) destaca que as discussões nessa área têm por objetivo avançar na busca de um trabalho com um caráter educativo-pedagógico adequado às especificidades das crianças de 0 a 6 anos, sendo que a principal característica que deve ser levada em conta é a dualidade cuidar e educar.

Aqui uma questão se faz importante: inserir profissionais designadas como professoras (com for- 
mação específica) resolverá os problemas relacionados a essa dualidade nas atividades? Essa professora fará ambas as atividades ou haverá uma divisão, na qual auxiliares (ou outro nome que convenha) farão o trabalho de "cuidado" com as atividades de higiene, alimentação e vestuário? Ou, como devem ser os profissionais para que consigam conciliar as atividades propostas na instituição de educação infantil aos objetivos de cuidados e educação numa visão única, integrada?

Ávila (2002) verificou que em uma estrutura na qual atuavam professores e monitores, as tarefas ficavam segmentadas e cada profissional assumia um tipo de atividade. O trabalho das monitoras, inclusive sob o ponto de vista das professoras, referia-se mais aos cuidados com as crianças e os professores acabavam por reproduzir um modelo escolar, ou seja, propunham atividades pedagógicas com o objetivo de desenvolver conteúdos nem sempre muito claros. A autora revela que ao aprofundar as observações notou que havia uma tentativa de organizarem a prática de forma mais unificada, de compartilharem as ações no cotidiano da creche, mas que o confronto na visão dessas práticas não auxiliava na integração necessária entre educar e cuidar.

Como deve ser então a formação das profissionais que atendem ao berçário?

O Ministério da Educação estipulou prazos para a formação dos profissionais que já estavam na prática, mas não norteou o que espera dessa formação. Palhares e Martinez (1999) discutem o Referencial Curricular Nacional para a Educação Infantil - RCN/Infantil - e indicam que ele pressupõe um "educador altamente qualificado, capaz não só de analisar tipos de brincadeiras e efetivá-las, considerando o potencial da atividade da criança, como também de prosseguir com a estimulação após cada resposta individual (...)” (p.9).

No entanto, a realidade mostra que não é esse o quadro do presente. Até hoje, em muitas creches, as profissionais que lidam com o berçário não têm sequer formação de segundo grau (Cerisara, 2002).

A partir da proposta de Kuhlmann Jr. (1999) de considerar a criança como ponto de partida para pensar no que deve ser oferecido nessas instituições, mais do que elaborar currículos com conteúdos a serem dominados pela criança, há necessidade de for- mar o profissional com domínio de conhecimentos que favoreçam e enriqueçam as experiências proporcionadas. Strenzel (2001) concorda e afirma que "um maior conhecimento das crianças e das especificidades da faixa etária por parte dos professores poderia trazer contribuições ao trabalho pedagógico desenvolvido" (p.4).

Azevedo e Schnetzler (2001), sugerem que a formação deixe de seguir a direção teoria-prática e parta da prática, iluminando-a com conhecimentos teóricos mais adequados à condição da criança como ser histórico e social que é. Mello (2001) ressalta que os professores devem perceber que sempre há uma teoria que sustenta e problematiza a prática educativa, e que essa percepção é imprescindível para a compreensão da prática, sendo que esse seria um trabalho de longo prazo e que deve partir da própria prática e suas dificuldades.

Os profissionais devem entender as atividades que já são realizadas no berçário, não havendo necessidade de grandes modificações. Devem ser traçados objetivos de acordo com a fase do desenvolvimento da criança, ou seja, de acordo com a maturidade. Dessa forma, o planejamento da instituição guiará as atividades realizadas. Isso é muito importante, porque não é uma proposta para mudar a atividade que se faz, e sim possibilitar aos profissionais ter consciência do porquê se faz em relação aos objetivos que integram o educar e o cuidar.

Para que essas propostas se concretizem, a participação de quem já atua e conhece as dificuldades e as possibilidades de trabalho junto a essa faixa etária é de extrema importância, pois muito do que é proposto para as crianças do berçário, já está sendo realizado pelos profissionais que lá atuam. No entanto, o desconhecimento de teorias que possibilitem delinear objetivos para as atividades desenvolvidas com as crianças diminui a auto-estima desses profissionais. Definir estratégias de formação desconsiderando a organização já existente poderá desestruturar o cotidiano dessas instituições, de seus profissionais e da sua clientela, sem garantir mudanças efetivas na qualidade dos serviços oferecidos.

A formação inicial do professor de berçário em nível médio e/ou superior, assim como a formação em serviço, deve passar pelo conhecimento da realidade, considerando as características da criança 
e o conhecimento adquirido ao longo dos anos pelos profissionais que já estão atuando nessas instituições.

\section{Considerações Finais}

Os resultados mostraram que os documentos oficiais que versam sobre educação infantil, pouco discutem a fase de 0 a 18 meses, deixando imprecisa a relação entre as atividades de cuidado e seu papel educacional. Essa imprecisão se reflete no discurso das responsáveis pela educação dessa criança.

A rotina da maior parte dos berçários se desenvolve baseada no papel de cuidar, pela própria especificidade da faixa etária, ou seja, a criança pequena é vista como um ser que deve ser cercado de cuidados de modo a promover um desenvolvimento sadio. Esse fato está diretamente relacionado ao modelo de creche implantado no Brasil, com características assistencialistas, que ainda hoje objetiva atender a uma parcela carente da sociedade - mães que não têm condições sócio-econômicas para ficar o dia todo com a criança.

Embora as profissionais consigam relatar aspectos que supõem a existência de relações entre o cuidado e a educação, enquanto desenvolvimento global da criança, estes se apresentam de forma descontextualizada e não como uma atividade planejada e rotineira das profissionais.

Esse aspecto justifica-se pela falta de formação dessas profissionais, que poderia ser incrementada através de programas que estimulassem a análise desta inter-relação (do desenvolvimento com as atividades do cotidiano infantil). Estes programas devem valorizar a prática existente e a partir dela reconhecer as especificidades da educação no berçário. Essa é uma das tarefas mais importantes de educadores e pesquisadores na área de formação de professores.

\section{Referências Bibliográficas}

Amorim, K.S., Yazlle, C. \& Rossetti-Ferreira, M.C. (1999). Saúde e doença em ambientes coletivos de educação da criança de 0 a 6 anos. Texto recuperado 11 mar. 2002: http:// www.ced.ufsc.br/ nee0a6/ROSSETTI.pdf.
Ávila, M.J.F. (2002). As professoras de crianças pequenininhas e o cuidar e o educar. Texto recuperado 27 mai. 2002: http://www.anped.org.br/ 25/tp25.htm\#gt7.

Azevedo, H.H. \& Schnetzler, R.P. (2001). Necessidades formativas de profissionais de educação infantil. Texto recuperado 11 mar. 2002: http:// www.ced.ufsc.br/ nee0a6/anped2001.html.

Batista, R. (2001). A rotina no dia-a-dia da creche: entre o proposto e o vivido. Texto recuperado 11 mar. 2002: http://www.ced.ufsc.br/ nee0a6/ anped2001.html.

Béziers, M.M. \& Hunsinger, Y. (1994). O bebê e a coordenação motora: os gestos apropriados para lidar com a criança. São Paulo: Summus.

Brasil. Ministério da Educação e do Desporto. Secretaria de Educação Fundamental (1998). Referencial curricular nacional para a educação infantil. Brasília: MEC/SEF. v.1.

Bujes, M.I.E. (2001). Governando a subjetividade: a constituição do sujeito infantil no RCN/Educação Infantil. Texto recuperado 11 mar. 2002: http://www.ced.ufsc.br/ nee 0 a 6 / anped2001.html.

Campos, M.M. (2002). A formação de profissionais de educação infantil no contexto das reformas educacionais brasileiras. Em J. OliveiraFormosinho \& T.M. Kishimoto (orgs), Formação em contexto: uma estratégia de integração (pp. x-xxiii). São Paulo: Pioneira Thomson Learning.

Cavicchia, D.C. (1993). O cotidiano da creche: um projeto pedagógico. São Paulo: Loyola.

Cerisara, A.B. (2002). O referencial curricular nacional para a educação infantil no contexto das reformas. Educ. Soc. [on line], vol. 23, n 80 [citado 24 março 2003\}, p. 326-345. Disponível na World Wide Web: http:www.sciel.br/ scielo.php?script=sci_arttext\&pid=S0101$73302002008000016 \& \operatorname{lng}=p t \& n r m=i s s o>$. ISSN 0101-7330.

Coutinho, A.M.S. (2002). Educação infantil: espaço de cuidado e educação. Texto recuperado 11 mar. 
188 Fabiana C. F. de Vitta

2002: http://www.anped.org.br/25/Tp25.htm.

De Vitta, F.C.F. (1998). Uma identidade em construção: o terapeuta ocupacional e a criança com retardo no desenvolvimento neuropsicomotor. Bauru: EDUSC.

Eckert, H.M. (1993). Desenvolvimento motor. São Paulo: Manole.

Eltink, C.F. (2000). Indícios itoçozadps por educadores para avaliar o processo de inserção de bebês em uma creche. Texto recuperado 11 mar. 2002: http://www.anped.org.br/0709.htm.

Felipe, J. (2001). O desenvolvimento infantil na perspectiva sociointeracionista: Piaget, Vygotsky, Wallon. Em C.M Craidy \& G.E.P.S. Kaercher (orgs.), Educação Infantil: pra que te quero? (pp. 27-37). Porto Alegre: Artmed Editora.

Fullgraf, J.B.G. (2001). Direitos das crianças à Educação infantil: inclusão ou exclusão? Texto recuperado 11 mar. 2002: http://www.ced.ufsc.br/ $\sim$ nee0a6/anped2001.html.

Gil, A.C. (1999). Métodos e Técnicas de Pesquisa Social. São Paulo: Atlas.

Kuhlmann JR., M. (1999). Educação infantil e currículo. Em A.L.G. Faria \& M.S. Palhares (orgs.), Educação Infantil pós-LDB: rumos e desafios (pp. 51-65). Campinas, SP: Autores Associados - FE/UNICAMP; São Carlos, SP: Editora da UFSCar; Florianópolis, SC: Editora da UFSC, 1999.

Lüdke, M. \& André, M.E.D.A. (1986). Pesquisa em educação: abordagens qualitativas. São Paulo: EPU.

Mazzilli, S., Rosalen, M.A.S., Barbosa, J.G., Giacomini, P.A. \& Rozineli, T. (2001). As "Diretrizes curriculares nacionais para a educação infantil" e os projetos pedagógicos das instituições de educação infantil. Texto recuperado 11 mar. 2002: http://www.ced.ufsc.br/ nee0a6/ anped2001.html.

Mello, M.A. (2001). A atividade mediadora nos processos colaborativos de educação continuada de professores: educação infantil e educação físi- ca. Tese de Doutorado, Universidade Federal de São Carlos, São Carlos.

Minayo, M.C.S. (2000). O desafio do conhecimento: pesquisa qualitativa em saúde. São Paulo: Hucitec; Rio de Janeiro: Abrasco.

Palhares, M.S. \& Martinez, C.M.S. (1999). A educação infantil: uma questão para o debate. Em A.L.G. Faria \& M.S. Palhares (orgs.), Educação Infantil pós-LDB: rumos e desafios (pp. 5-18). São Carlos: Editora da UFSCar.

Pereira, V.C. \& Emmel, M.L.G. (1999). Um estudo sobre o desenvolvimento de habilidades em crianças de 0 a 2 anos através do brinquedo. Temas sobre Desenvolvimento, 8 (43), 9-14.

Prates, C.S. \& Oliveira, M.S. (2001). Temas de Saúde em Instituições de Educação Infantil. Em C.M Craidy \& G.E.P.S. Kaercher (orgs.) Educação Infantil: pra que te quero? (pp.3 9-60). Porto Alegre: Artmed Editora.

Rapoport, A. \& Piccinini, C. A. (2001) O ingresso e a adaptação de bebês e crianças pequenas à creche: alguns aspectos críticos. Revista Psicologia Reflexão e Crítica, 14(1), 81-95.

Rossetti-Ferreira, M.C., Amorim, K.S. \& Silva, A.P.S. (2000). Uma perspectiva teórico-metodológica para análise do desenvolvimento humano e do processo de investigação. Revista Psicologia Reflexão e Crítica, [on line],13(2). [citado 18 março 2003], p.281-293. Disponível na World Wide Web: <http://www.scielo.br/ scielo.php?script=sci_arttext\&pid=So1o2$79722000000200008 \&$ lng $=$ pt $\& n r m=i s s o>$. ISSN 0102-7972.

Silva, A.P.S. \& Rossetti-Ferreira, M.C. (2000). Desafios atuais da educação infantil e da qualificação de seus profissionais: onde o discurso e a prática se encontram? Texto recuperado 11 mar. 2002: http://www.anped.org.br/0707t.htm.

Souza, P.N.P. \& Silva, E.B. (2001). Como entender e aplicar a nova LDB: lei $n^{\circ}$ 9.364/96. São Paulo: Pioneira Thomson Learning.

Strenzel, G.R. (2001). A contribuição das pesquisas 
dos Programas de Pós-Graduação em Educação: Orientações pedagógicas para crianças de 0 a 3 anos em creches. Texto recuperado 11 mar. 2002: http://www.ced.ufsc.br/ nee0a6/ anped2001.html.

Thiessen, M.L. \& Beal, A.R. (1995). Pré-escola, tempo de educar. São Paulo: Ática.

Thiollent, M.J.M. (2002). Metodologia de pesquisaação. São Paulo: Cortez.

Trabalho derivado de Tese de Doutorado em desenvolvimento no Programa de Pós-Graduação em Educação Especial da UFSCar, com apoio financeiro do CAPES. 